Draft Version, posted on July 6, 2021.

This paper has not (yet) been published and is not therefore the authoritative document of record. The final version may differ.

\title{
Applying Bodily Sensation Maps To Art-Elicited Emotions: An Explorative Study
}

Gemma Schino ${ }^{1}$, Lisa-Maria van Klaveren², Héctor G. Gallegos González ${ }^{3}$, Ralf F. A. Cox ${ }^{1}$ ${ }^{1}$ Department of Psychology, University of Groningen

${ }^{2}$ Center for Evidence Based Education (CEBE), Institute of Education and Training (IOO), Amsterdam University Medical Center 3Department of Arts, Culture, and Media, University of Groningen 


\begin{abstract}
Art is known to give rise to a large range of emotions in people. These emotions are associated with bodily sensations felt in various regions of the body and subjective feelings. The current study applies Bodily Sensation Maps (BSMs, Nummenmaa et al., 2014) as a tool to measure art-elicited emotions by charting bodily sensations onto a body map. Through a web survey, 90 participants viewed 36 new media visual artworks. After each artwork, they were asked (1) to point out the regions of their body in which they felt activity getting stronger or weaker, (2) to select, if appropriate, up to two primary emotion words being anger, disgust, fear, happiness, sadness or surprise, and (3) to rate the intensity of the subjective feeling on a continuous scale. By allowing two primary emotion words for each artwork, participants could report more complex emotions. Among complex emotions, bittersweetness, delight, despair, and repugnance occurred the most, and delight stands as the most frequently used. Results show that BSMs are a resourceful method to investigate simple and complex emotions elicited by art in terms of bodily sensations and subjective feelings. Interestingly, we found that art-elicited emotions were always characterized by increased activity in the head area. This study provides novel insights into the nature of artelicited emotions and how they are experienced in the body, as well as how they are related to emotions in everyday life.
\end{abstract}

Keywords: Art, Bodily Sensation Maps, Subjective feelings, Embodiment, Emotions. 
BODILY SENSATION MAPS IN NEW MEDIA VISUAL ART ENCOUNTERS [PREPRINT]3

\section{Applying Bodily Sensation Maps To Art-Elicited Emotions:}

\section{An Explorative Study}

\section{Emotions}

Emotions can be described as affective states that include physical and psychological changes (Ekman, 1970). While physical changes are related to autonomic responses in the body that occur as an emotion arises, psychological changes represent the qualitative experience of the emotion. Following the component process model of emotion, five components can be identified: the cognitive (appraisal), the neurophysiological (bodily sensations), and the motivational (action tendencies) as well as the components of motor expression (facial and vocal expressions) and subjective feeling (Scherer, 2005). The synchronized interplay of these components in response to an external or internal stimulus constitutes an emotion. In the process of emotion, the cognitive or appraisal component refers to the information processing of a stimulus event, and its evaluation. Besides, the stimulus event elicits physiological response patterns, such as feeling shivers, muscles relaxing or trembling and changes in respiration activity. The adaptive action tendencies (motivational component) and motor expression have a strong impact on the action that is chosen (i.e., fight or flight) as well as how the emotion is communicated (i.e., crying), respectively. The subjective feeling or experience is summarized in emotion words, "reflecting a unique experience of mental and bodily changes in the context of being confronted with a particular event" (Scherer, 2005 p.712). Hence, subjective feelings of an emotional episode are underpinned by patterns of the different components listed above.

Ekman (1970) asserts the existence of six psychologically primitive (i.e., basic) emotions: anger, disgust, fear, happiness, sadness, and surprise. They elicit biologically based response patterns, and they can fuse, merge altogether easily taking the shape of new complex emotions ${ }^{1}$ (Ortony \& Turner, 1990). Emotions elicited by art are no exception (Brown et al., 2011). Therefore, the present study will focus on how the two components of study.

${ }^{1}$ Nonbasic, or complex, emotions will be discussed further in the Methods section of this 
the emotion, namely bodily sensations, and subjective feeling, are intertwined with each other in response to art (see Damasio \& Carvalho, 2013; Russell, 2003).

\section{Art-elicited emotions}

According to Cupchick (2013), emotions in response to art can be divided into two reactions: the dimensional and the categorical. Whereas the former reactions are closely tied to bodily states of arousal elicited by an artwork, the latter pertains to primary emotions and “emphasizes spontaneity or empathetic reaction to art” (Pelowski et al., 2016 p. 13). With regard to the dimensional reaction, most philosophical aestheticians have claimed that visual arts "produce a variety of responses ranging from calm contemplation to "aesthetic emotion" in which physiological arousal is not included” (Konečni, 2015 p. 306). According to philosophical aesthetic theories, 'refined' or 'aesthetic' emotions are detached affective states that are different from everyday psycho-biological emotions for practical purposes (i.e., utilitarian emotions) (James, 1890; Ribot, 1987; Sully, 1892). Importantly, against this school of thought, we explicitly use the word 'art-elicited' instead of 'aesthetic' to move away from the traditional assumption that aesthetic emotions are only about beauty and enjoyment for their own sake (Sully, 1892) without accompanying bodily alteration (James, 1890). Whether experiencing artwork elicits a special class of emotions or not remains a matter of debate. Aware of this controversy on the nature of emotions elicited by art, we are open to the possibility that emotions felt during the artistic encounter can account for bodily changes and a wider range of subjective feelings so that emotions as responses to artworks may be merged altogether with emotions that deal with important events in our lives. 'Artelicited emotions' used throughout this paper refers to the emotion provoked by a stimulus that is an artwork, without assuming they lack defining features of emotions such as bodily alterations or, in some cases, negative affect. The inclusion of negative affect marks a pivotal point for art theories. Art is able to evoke adverse reactions such as disgust, queasiness, or anger by mirroring the emotions expressed in an artwork (Freedberg \& Gallese, 2007). Cooper and Silvia (2009, p. 113) claim indeed that "people appraise art in ways that evoke 
hostile emotions, [...], in short, some art makes some people mad”. Again, Menninghaus et al. (2017) claim that arts do not reduce or erase the negative emotional responses.

The present study considers that all basic emotions, their nuances, and combinations can occur in art encounters, thus seeing the basic-emotion theories as eligible in the context of art (Juslin, 2013a). We made use of these theories in the present study to obtain descriptors for the emotional experience of the participants towards artworks although not inclusive of typical aesthetic feelings (Juslin, 2013b; Marković, 2010). We validated whether emotions arise in the same way in the body either when they are evoked by visual artworks as proposed in the present research, or by different stimuli used in previous studies.

\section{Embodiment}

Gallese (2001) propose that art can deploy liberated embodied simulation, whereby the human brain is assumed to map actions, emotions, and sensations onto the viewer's sensorymotor and visceromotor neural representations through the immersive state that art can put the viewer into (Gallese, 2017; Rizzolatti et al., 1996). Noticeably, embodied empathetic feelings do not occur exclusively as a response to figurative artworks (Freedberg \& Gallese, 2007). Bodily involvement and empathetic movements can be experienced also in nonfigurative artworks, where the viewers engage with the gestures of the artist. Hence, it is considered both figurative and nonfigurative artworks can evoke embodied simulations. Likewise, Johnson claims that "perception, imagination, and feeling are aligned with the bodily dimension" (1987, p. xxv), asserting that whenever a projection of selves and bodies into an artwork occurs, the embodiment follows. Artworks give rise to bodily movements in the viewer (cf. Brinck, 2018; Fuchs \& Kochs, 2014) empathizing a relationship between emotional states and levels of physiological arousal of the viewer (Eskine, Kacinik \& Prinz, 2012; van Klaveren, Ueding \& Cox, 2019). Several studies found that artworks are able to elicit distinct movement patterns in the viewer, such as leaning posture and eye movement which are subtle indicators of people's attunement to the environment (Buswell, 1935; Ganczarek et al., 2015; Kapoula et al., 2011). These subtle movements are dynamically interrelated with the subjective feeling in response to art. Thus, this interplay is modulated 
by cognitive and emotional processes underlying the experience of a work of art (cf. Cova \& Deonna, 2014; Leder et al., 2004; Pelowski et al., 2017). Consequently, art-elicited emotions harmonize somatosensory, emotional, and motor systems, and eventually, result in what Esrock (2018) terms 'transomatizations'. Transomatizations are empathetic embodied processes in which viewers (re-)evaluate the bodily component in light of the artwork. In artistic encounters, not only the viewer's body and mind are engaged in the emotion felt as in any other emotional event, but also in the artwork. "Viewers can experience themselves, via their bodies, within the artwork, or containing the artwork. Where emotion is understood to have a bodily component, [...] emotions, too, can be felt in these shifts of embodied experience" (Esrock, 2018, p. 189). While looking at art, viewers may fall into a state of consciousness connected to emotion. These moments are not passive nor detached: they occur when the body and mind are engaged in a voluntary effort (Csikszentmihalyi, 1990).

To conclude, emotions provoked by artworks can give rise to an interplay of bodily sensations and a variety of subjective feelings. Art elicits physical changes in the body which are an important defining feature of emotions in general, such as heat in the face, tightness in the jaw or shoulders, shivers down the spine. That is, where and how happiness feels happy, or anger feels angry when looking at an artwork. The self-awareness of internal bodily states can specify sensory information of the affective process (Jung et al., 2017). Therefore, it should not be assumed that art-elicited emotions are only cognitive or detached by nature as suggested by traditional theories of philosophical aesthetics but are perceived and evaluated in the body. Looking at art has the potential to give rise to emotions that are subjective and embodied (see, e.g., Esrock, 2010; Esrock, 2018; Gernot, Pelowski, \& Leder, 2018). To grasp the relationship between art and emotions in different facets, we investigated the embodied nature of art-elicited emotions by validating a new way to chart them (Nummenmaa et al., 2014).

\section{Bodily Sensation Maps (BSMs)}

Nummenmaa and colleagues (2014) have designed a self-report software called emBODY. This tool allows people to highlight body regions that are activated or deactivated 
during emotional arousal on an empty body silhouette. It demonstrates how bodily sensations in emotional contexts are spatially distributed across the body in specific and consistent patterns (Jung et al., 2017). Based on this topographical tool, heatmaps known as Bodily Sensation Maps (BSMs) can be calculated. The BSMs have been used extensively in multiple studies including different scenarios and various populations (Nummenmaa et al., 2018; see also Novembre et al., 2019; Volynets et al., 2019). They can identify a broad spectrum of emotions, ranging from happiness, interest, guilt, disgust to embarrassment, among others. It reinforces the idea of using new biomarkers - such as the BSMs - to detect art's ability to move people figuratively and literally. Therefore, BSMs constitute a research tool that affords the nature of viewers' emotions in response to art. To the best of our knowledge, the topographic tool has not yet been applied to investigate art-elicited emotions. Due to art's particular potential for induction of emotional responses, it can encourage both introspective processes (Pelowski et al. 2017) and interoceptive processes (Esrock, 2018) in viewers. The latter processes help the viewers to read their own bodies as material for transomatization. Interoception plays an important role in the accuracy of "visible presentation [such as BSMs] of affective perception and its link with physiological states" (Jung et al. 2017 p.11).

\section{The present study}

The present study investigated whether BSMs constitute a valid instrument to measure a person's emotions in the art domain, without being exclusively limited to positive aesthetic-specific evaluations of pleasure, enjoyment, or fascination. To this end, we used BSMs as a means to detect participants' bodily sensations related to art-elicited emotions while viewing 36 artistic stimuli. After each artwork, participants were asked to point out the regions of their body in which they felt activity getting stronger or weaker using the BSMs (i.e., activations and deactivations), then to express their subjective feelings by selecting up to two primary emotion words (anger, disgust, fear, happiness, sadness, and surprise), and lastly to rate the intensity of the subjective feeling on a continuous scale. Concretely, we addressed the following research questions: (1) To what extent do the artworks give rise to 
bodily sensations in the participants? To answer this, we analyzed the counts on the BSMs to assess the location and frequency of activations and deactivations in the body upon viewing the selected new media (i.e.: digital, Quaranta, 2014) paintings. (2) To what extent do the artworks elicit subjective feelings in the participants (emotion words and their rated intensity)? (3) How are bodily sensations and subjective feelings related in art-elicited emotions? Finally, this study explores the application of BSMs in an artistic context by comparing our findings with previous literature (García-Magariño, Chittaro, \& Plaza, 2018; Jung et al., 2017; Nummenmaa et al, 2018; Novembre et al., 2019). This leads to a final, exploratory, and qualitative research question: (4) Are the topographical depiction of emotional responses in the body generated in previous studies similar to the ones evoked by new media visual artworks?

\section{Methods}

\section{Participants}

Ninety-two first-year Psychology students at the University of Groningen participated in the experiment. They were rewarded with course credits upon completion of the survey. Only participants with normal vision (with or without optical adjustments) were invited to participate in the experiment. Participants were asked to perform the experiment without physical (e.g., other people around), physiological (e.g., being hungry or tired) or psychological (e.g., being more emotional than usual) distractions as these might interfere with their emotional state and perception of their body and might have an impact on the performance of the task. Two participants were excluded from the analysis as they responded respectively only to $16.66 \%$ and $12.04 \%$ of the experiment. The final sample used for the analysis, therefore, consisted of 90 participants (29 males, 61 females) with an average age of 20 years (from a minimum of 17 to a maximum of $24, \mathrm{SD}=1.56$ ). The study was approved by the Ethics Committee Psychology of the University of Groningen (research code: PSY-1920S-0250) and was conducted according to the Dutch ethical standards for scientific research. 
BODILY SENSATION MAPS IN NEW MEDIA VISUAL ART ENCOUNTERS [PREPRINT]9

\section{Materials}

\section{Artworks}

A careful selection of 36 new media artworks was carried out. The selection was limited to new media figurative paintings as the digital format allows participants to appreciate the artworks as they were meant to be experienced, that is on a screen.

Preliminary informal polls and sorting among the authors of the paper have been conducted according to the following criteria: the variety of figurative artistic styles, equal presence of female and male figures, dimension, image aspect ratio, and variety of potential elicited emotions. Firstly, a broad selection of approximately 200 figurative (or representational) artworks has been collected through digital art gallery websites, namely ArtStation (https://www.artstation.com/) and DeviantArt (https://www.deviantart.com/). Secondly, the collection of stimuli has been narrowed down to 70 stimuli. Ten artworks were chosen for each basic emotion category (anger, disgust, fear, happiness, sadness, surprise); and ten ones aiming at eliciting a neutral state. The use of figurative paintings ensured that the emotions portrayed in the artworks could be read more easily by the participants (Konečni, 2015). Lastly, the stimuli have been filtered by artists and their respective styles (realism, impressionism, comics, surrealism, cartoon, manga). The artists among the collection who featured artworks in different formats (portrait, landscape, and square pictures), displaying diverse emotions and with a variety of figurative content (humans and non-human) were then chosen as the final selection. In fact, ten stimuli of the 36 used in the present study (stimulus 6, 7, 8, 9, 14, 15 17, 18, 21, and 29) represent as main content objects or landscapes $(n=6)$ and monsters $(n=4)$. The remaining stimuli (i.e.: 26 out of 36$)$, on the other hand, depict human bodies and faces. Therefore, artworks with recognizable images and objects were then selected purposely for this study. The understandable and prototypical features of figurative paintings usually induce emotional responses without difficulty in laypersons (O'Hare, 1976; Cupchik \& Gebotys, 1988; Martindale, Moore, \& Borkum, 1990; Hekkert \& van Wieringen, 1996; Millis, 2001). We were thus able to establish a preconceived notion of the general emotion each artwork would convey (Hayn-Leichsenring, 2017; 
Wagner et al., 2014). Once the final assortment was decided, the permission of use under the Creative Commons (CC) license for such art pieces was obtained from each of the artists. Six artworks of six different artists each have been randomly used as artistic stimuli for the current study (see Appendix A and online supplemental material for detailed information).

\section{Bodily sensations: body regions and their activity}

The experiment was generated online using Qualtrics software so that each participant could take part in the experiment on their computer.

To replicate the emBODY tool by the Nummenmaa Lab (https://emotion.utu.fi/), the Heat Map Questions have been set up to gather information on the locations in which people felt activity in their bodies. Body activity was divided into two categories: (1) activations in the body (or activity getting "stronger", such as heart pounding, flush in the face, muscles tensing, etc.); (2) deactivations in the body (or activity getting "weaker", for instance, feeling weak limbs, getting pale, light-headed, numb, feeling faint and woozy body parts). These activities can be more or less intense depending on the emotional event. For this reason, participants could click up to ten times to indicate the respective parts of the body. For it to be as close as possible to emBODY, the same human body silhouette image $(265 \times 620$ pixels) and instructions have been used. We adapted the instructions by referring to 'point' instead of painting and coloring and specific guidelines for the heat map question were added (i.e., "You can click up to 10 times. Try to be the more accurate as possible. If necessary, use more clicks to stress a particular zone where the feeling is more intense.”).

The heat maps provide us with coordinates for each selected click-point. Participants were let free to leave the body silhouettes blank, if appropriate. Moreover, to further investigate bodily patterns of sensation, we defined nine customized regions within the silhouettes (head, face, neck, upper limbs, hands, chest, abdomen, legs, feet) and reported the number of respondents who click on each of them. Nevertheless, during the analysis, following the example of previous literature (see Novembre et al., 2019), we combined the categories into five to facilitate the analysis. The final bodily regions are the head, upper limbs, chest, abdomen, and lower limbs. 


\section{Emotion words: To describe the type of subjective feeling and its intensity}

In addition to the heatmaps, we assessed participants' subjective feelings by selecting emotion words (happiness, surprise, anger, fear, disgust, or sadness) and rating their intensities in relation to the bodily sensations.

Only these primary universal emotion words were provided to the participants, for three reasons: (i) to use familiar terms commonly used in emotional experiences (Prinz, 2004), (ii) to ease the categorization labeling of the BSMs during the analysis, and (iii) to retrace the theoretical background and methodology used by Nummenmaa et al. (2014). To account for the possibility that participants did not experience a particular subjective feeling regarding a specific artwork, not responding to the question was also an option. In this case, the subjective feeling was interpreted as neutral. Participants could combine up to two basic emotion words indicating a more complex subjective feeling if needed (see Table 1). Four combinations of emotion words that most frequently occurred have been analyzed in this study: bittersweetness, delight, despair, and repugnance. The categories for these emotion words have been based on Plutchik's emotion wheel (1980) and Ekman's universal emotions (1970). However, we adopted an elaboration of Plutchik's emotion wheel revised by TenHouten (2013).

\section{Table 1}

Dyads or complex emotions (compositions of two emotion words) (Plutchik, 1991; TenHouten, 2013).

\begin{tabular}{lllllll}
\hline & Anger & Disgust & Fear & Happiness & Sadness & Surprise \\
\hline Anger & Anger & Contempt & Frozenness & Pride & Envy & Outrage \\
Disgust & Contempt & Disgust & Repugnance & Morbidness & Remorse & Unbelief \\
Fear & Frozenness & Repugnance & Fear & Guilt & Despair & Awe \\
Happiness & Pride & Morbidness & Guilt & Happiness & Bittersweet. & Delight \\
Sadness & Envy & Remorse & Despair & Bittersweet. Sadness & Disapproval \\
Surprise & Outrage & Unbelief & Awe & Delight & Disapproval & Surprise \\
\hline
\end{tabular}

Note. Bittersweet. $=$ Bittersweetness. 
According to Plutchik (1980), the combination of fear and disgust results in shame. This formulation would be fair if one would interpret shame just as a feeling that -per definition- is associated with negative thoughts and discomfort (Tracy \& Robins, 2007). Nonetheless, shame brings with it cultural considerations, and, in western cultures, it is usually associated with embarrassment or prudishness (Russell, 1991). We think it would be more appropriate, then, to embrace the idea that the combination of fear and disgust is repugnance (TenHouten, 2013, p. 18), which seems to be also coherent in the context of artistic experiences (García, 2019). By doing so, the study explores art-elicited emotions beyond the traditional categories of pleasure or beauty.

\section{Procedure}

From the beginning, the participants were fully informed of the research's purpose. It was explained to them that the study involved questions about the feelings they perceive in their body in response to artworks. Moreover, participants were provided with an information form for further details about the procedure. Importantly, it was clearly stated in the information form and the instructions for the experiment that participants will look at artworks. Therefore, we expected that participants anticipating artworks engaged in artistic experience (Hayn-Leichsenring, 2017). Subsequently, a check to ensure their pre-affective state has been conducted. This go/no-go measure functioned as a screening instrument. Subjects with second thoughts about their emotional pre-condition were asked to participate in the experiment at a more suitable time. Moreover, this brief check also worked as an emotional scan. Doing this before the stimuli display can prevent emotional hijacking (Boyer, 2011). Besides, participants are more self-conscious and convey the emotional attitude they want to convey. Upon agreement to participate, the online experiment started. Demographic questions (age, gender, and whether they are native English speakers or not) were asked first, followed by the task instructions and a step-by-step sample of the trial serving as a tutorial. Once the participant felt ready, the experimental trials started. 


\section{Figure 1}

Experimental procedure

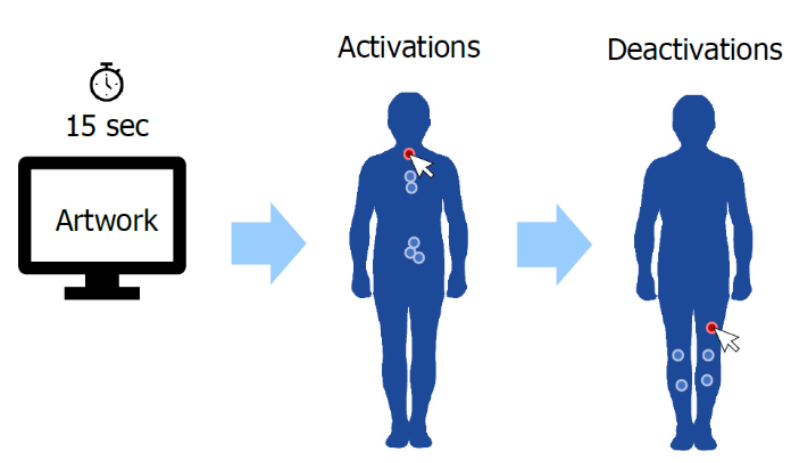

1)

2)

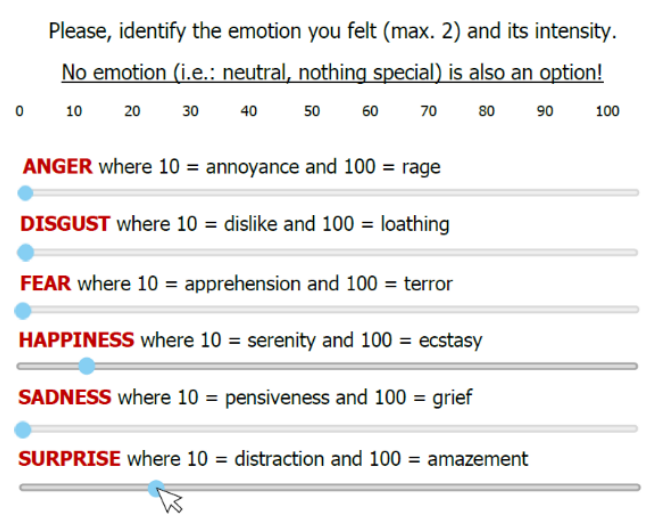

3)

Figure 1 shows step by step the trial's procedure as follows:

1) Each new media artwork was randomly displayed on the screen for 15 seconds.

2) At the end of each observation, the participant was asked to indicate the regions and intensities of bodily sensations by clicking up to ten times on two empty body silhouettes. They could point out body regions in which activations and deactivations were taking place (in the first and second silhouette, respectively).

3) After this task, the participant selected up to two emotion words within the cluster of the six basic emotions to label that bodily sensation. Sliders were used as a more interactive and intuitive way to quantify the intensity of the emotions. Rather than simply picking an emotion word and selecting its intensity on a scale point, respondents could use a slider handle to indicate the intensity level of the emotion. Additional labels about the intensity range of emotions helped participants to find the appropriate answer (see Figure 1). Participants were provided with instructions and information form that cleared out they should choose the closest option of emotion word(s) to label the bodily sensations they reported in the BSMs and that no slider selection was considered as a response of nothing special, hence a neutral state. While 
the selection of two sliders was interpreted a posteriori in the analysis as a complex emotion derived from the combination of the two basic emotions (see Table 1). The participants could choose a maximum of 2 sliders to combine emotions. For instance, if an artwork conveyed them a pleasant emotion, they could: use the most appropriate slider for the basic emotion they felt (e.g.: only happiness) and drag the pointer to the desired amount; or drag the pointer of two sliders (e.g.: happiness and surprise, as shown in Figure 1) so that the respondents could create the closer combination to their current subjective feeling (e.g.: delight).

The entire experiment lasted 38.2 minutes on average $(\mathrm{SD}=19.7)$. We excluded only one participant from these descriptive statistics since their response time of 20 hours stands as an outlier. We presume the participant took a break and resumed the experiment the day after it without closing the tab to prevent the loss of progress. At the end of the experiment, participants were thanked for their time and then provided with a debriefing form to emphasize the importance of their participation.

\section{Data preprocessing and analysis}

Data preprocessing was carried out using customized 'COUNTIFS' scripts in Excel (Microsoft 365, v. 2016). Based on the raw dataset, we identified patterns of bodily sensations by dividing the body silhouettes' coordinates into five regions of interest (ROIs). Body regions are shown in Figure 2.

They allowed us to use accurate frequencies instead of the cartesian coordinates (i.e., xy-coordinates of all points in the image) for our analysis. Coordinates and frequencies were discerned into 22 discrete emotional categories (namely, the six basic emotions, the neutral state, and the 15 dyadic states) to ease the computation of BSMs. 


\section{Figure 2}

Regions of interests (ROIs) in the body defined by pixel-point coordinates

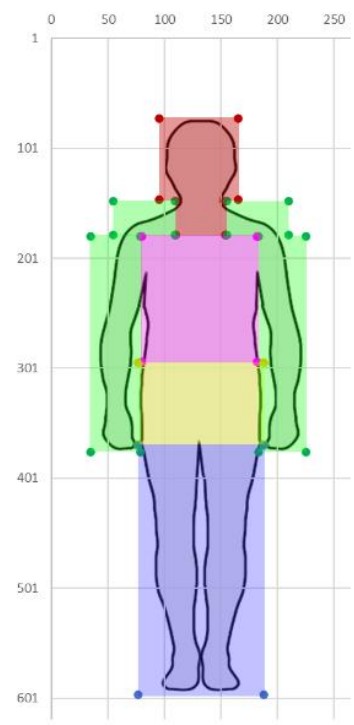

Note. The ROIs identified within the silhouette are (from top to bottom): head, chest, abdomen, upper limbs (shoulders, arms, and hands), lower limbs (legs and feet). For more information, see 'Bodily Regions COORDINATES.xlsx' in the online supplemental material.

\section{Art-elicited bodily sensations}

First, a frequency table was created to preliminarily evaluate which of the defined body regions were activated or deactivated the most for each artistic stimulus across all 90 participants (see Table $1 \mathrm{~B}$ and Table $2 \mathrm{~B}$ in Appendix B). Then, cross-tabulations between the counts of both activations and deactivations of body regions and stimuli were generated. Finally, to formally assess the association between bodily sensations in terms of activations and deactivations and the artworks, a chi-square test was performed to check the statistical significance of such crosstabs.

\section{Art-elicited subjective feelings}

We used data counts (see 'Frequencies (.xlsx)' file of the online supplemental material accompanying the article for full access to the data) to gain information about the dominant subjective feelings elicited by each artwork. In this way, we could compare the frequencies of reported emotion words and the rated intensity for each artwork. Among the complex emotions only repugnance, despair, bittersweetness, and delight have been further explored. 
These combinations had an occurrence rate greater than $5 \%$ in the responses given throughout the entire survey. Respectively, they constitute the $7.10 \%, 7.41 \%, 5.49 \%$, and $11.85 \%$ of all the responses concerning the subjective feelings reported by the participants as reported in Figure 3. The remaining dyads (pride, remorse, unbelief, guilt, disapproval, frozenness, envy, morbidness, outrage, and awe) singularly occurred with a slim rate, ranging from a minimum of $0.65 \%$ (pride) to a maximum of $3.53 \%$ (contempt).

In this experiment, participants could rate the intensity of basic emotions by positioning a slider on a $0-100$ scale. The combination of two basic subjective feelings was interpreted as a new complex one. To assess the intensity of the complex subjective feeling, the square-root function on the sum of two squares has been computed. That is, we calculated the magnitude of the vector in Euclidean coordinates, from $(0,0)$ to $(\mathrm{x}, \mathrm{y})$, where $x$ and $y$ are the intensity scores (i.e.: coordinates) of the two basic subjective feelings as components of a complex emotion. By doing so, the intensity of the subjective feeling of a complex emotion was defined as the length of the resultant vector of the combination.

\section{Figure 3}

Percentages of occurrence of combinations of subjective feelings

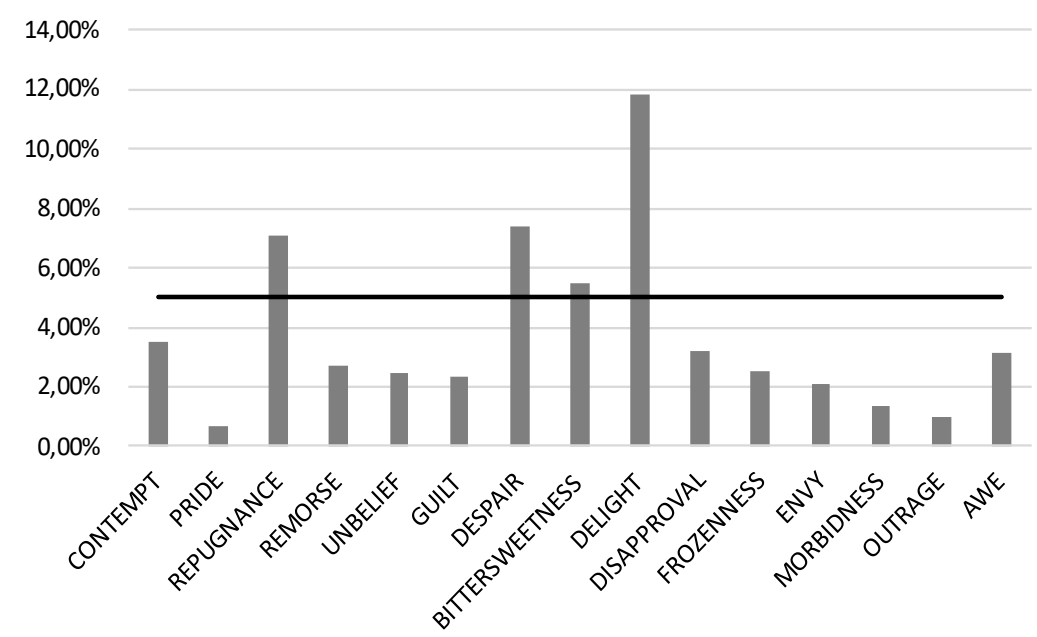

Note. The chart shows the percentage (on the vertical axis) of the combinations of subjective feelings (on the horizontal axis) across participants among the 36 stimuli. The line sets a threshold under which combinations of subjective feelings were not further examined in the present study due to their very low presence in the experiment. 
Finally, we normalized all individual scores so that the magnitude of the subjective feeling could range from o to 1 . In other words, each intensity score of the subjective feelings has been divided by the square root of the maximum magnitude achievable ${ }^{2}$. A subjective feeling of a primary emotion could reach a maximum of 0.71 , and the highest intensity value for a complex emotion was 1 . Intensity values were studied through histogram shape analysis (i.e., skewness and kurtosis).

\section{Art-elicited emotions: Combining bodily sensations and subjective feelings}

No consistent normal distribution was observed in the data. Hence, non-parametric statistics were used. To assess significant activations and deactivations, in each body region of the emotion-specific BSMs, One-Sample Wilcoxon tests against zero were performed. Moreover, pairwise comparisons between BSMs for each subjective feeling and the neutral state were carried out with the Wilcoxon matched-pair signed-rank test. Counts for each body region in relation to a specific subjective feeling for each stimulus were tested against the counts for the neutral state, adding up to ten comparisons (i.e., five comparisons for activations in the body and five for deactivations) by the final ten selected emotion words excluding the neutral state.

In all the Wilcoxon analyses, family-wise error (FWE) correction was used to handle false positives due to multiple comparisons and repeated testing. Hence, to obtain a corrected type I error of $\mathrm{p}<.05$ for the whole body was corrected by exact-significance. Furthermore, to assess the existence of a relationship between bodily sensations and subjective feelings in art-elicited emotions, a chi-square was performed for both body activations and deactivations and emotion words.

\section{Topographical depictions of art-elicited emotions}

We adapted Nummenmaa and colleagues' methodology (2014) to our dataset by recreating BSMs based on the data collected during the web survey. The xy-coordinates of all points per emotion were plotted into the original silhouette image via Power Map, a 3-D

2 The highest value on the intensity scale is 100 . To normalize the intensity scores, we divided each of them and the vector units of complex subjective feelings by $\sqrt{100^{2}+100^{2}}$ 
spatial visualization add-in fully integrated into all versions of Excel 2016 for Windows. We also reproduced the color scales used in the emBODY software. In the case of highly intense agglomerations of point, the extreme colors turn to white. Click-points outside the body silhouette were masked out as per protocol (Nummenmaa et al., 2014). This way we attained a visual representation at the population level for subjective feelings of primary and complex emotions as well as of the neutral state. This was especially helpful in gaining insights into how emotions were embodied across artworks. Coordinates and their topographical representations are available as online supplemental material in a dedicated folder entitled 'BSMs'.

\section{Hierarchical Clustering}

Chi-square values between sets of frequencies body activity for each art-elicited emotion were plotted into a proximity matrix, proceeded by hierarchical cluster analysis.

This agglomerative procedure with complete linkage ('Furthest Neighbor' method in SPSS) was run to test how similar or different the art-elicited emotions in terms of their bodily responses were. It provided us with a dendrogram to compare with the one obtained by Nummenmaa et al. in their original paper (2014). In our sample, we aimed at replicating their results and relate them to testing commonalities across BSMs' clusters of emotion.

\section{Results}

\section{Relationship between bodily sensations and artworks}

We first investigated the potential association between bodily sensations in terms of activations and deactivations and artistic stimuli presented in the experiment. To achieve that, a cross-tabulation analysis was used (see Table 1B and Table 2B in Appendix B). Considerably more points were collected from the activation maps (9998 points) compared to the deactivation maps (6852 points). Conceivably, this indicates that activity getting stronger in the body is perceived more easily than activity getting weaker. Interestingly, both activation and deactivation occurred with a certain region-specificity. The former was mostly observed in the head, whereas the latter was generally limited to the lower limbs (see Table 2). 
BODILY SENSATION MAPS IN NEW MEDIA VISUAL ART ENCOUNTERS [PREPRINT]19

\section{Table 2}

Summary table for frequencies of activations and deactivations in the body

\begin{tabular}{|c|c|c|c|c|c|c|}
\hline \multirow{2}{*}{$\begin{array}{c}\text { Type of body } \\
\text { activity }\end{array}$} & \multicolumn{5}{|c|}{ Body Regions } & \multirow{2}{*}{$\begin{array}{l}\text { Total } \\
\text { Counts }\end{array}$} \\
\hline & Head & Chest & Abdomen & Lower Limbs & Upper Limbs & \\
\hline Activation & 3128 & 2340 & 1640 & 879 & 2011 & 9998 \\
\hline Deactivation & 553 & 758 & 892 & 2806 & 1843 & 6852 \\
\hline
\end{tabular}

The highest frequency of activations and deactivations were recorded for Stimulus 23

(347 points) and 18 (226 points), respectively, whereas the lowest frequency of activations and deactivations were detected for Stimulus 9 (198 points) and Stimulus 7 (139 points), respectively. Two chi-square tests were performed testing against the following null hypotheses: (1) Stimuli are not associated with Activations of body regions, and (2) Stimuli are not associated with Deactivations of body regions (see Table $1 \mathrm{C}$ and Table $3 \mathrm{C}$ in Appendix C). Stimuli and activations of body regions showed a significant $\left(\chi^{2}(4)=\right.$ 1223.288, $p<$.001), although rather weak association according to Cramer's $\mathrm{V}$ test of the strength of association $(\mathrm{V}=0.175)$. Thus, the first null hypothesis can be safely rejected. The second null hypothesis can also be rejected as the association with deactivations of body regions is again weak $(\mathrm{V}=0.117)$ but reliable $\left(\chi^{2}(4)=377.392, p<.001\right)$.

\section{Relationship between subjective feelings and artworks}

A preliminary analysis was performed to determine the frequencies of specific subjective feelings evoked by the artworks in the 3240 trials of our experiment ( 36 stimuli for each of the 90 participants) (see Table 3B and Table 4B of Appendix B). Delight was the most frequent emotion word as it was selected 384 times, whereas the least chosen was Anger (55 times). In general, participants chose more frequently to combine emotion words rather than pick only one, suggesting that visual art provokes subjective feelings of complex emotions in people. Additionally, Delight was elicited in 35 (out of 36) stimuli, whereas Happiness (the second most selected emotion words) occurred only in 28 stimuli. Stimulus 7 (see Appendix A) generated Repugnance in 40\% of the participants (36 out of 90), which indicates that certain artworks consistently evoke the same subjective feelings. 


\section{Figure 4}

Histograms of standardized intensity scores for each subjective feeling

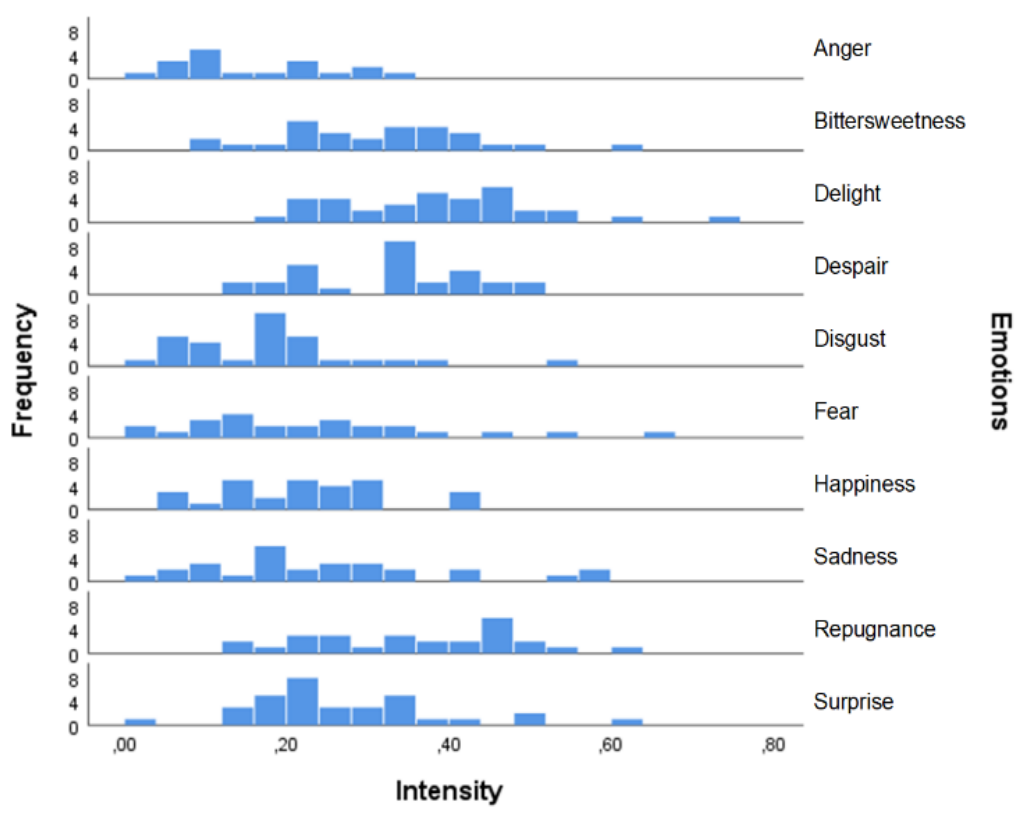

Note. The x-axis marks and labels with the standardized intensity values from the dataset, while the y-axis for counting data values.

Nevertheless, only eight stimuli had a rate of agreement greater than $30 \%$, implying that there was a certain degree of subjectivity of the art-elicited emotions in terms of subjective feelings. As Figure 4 shows, the reported intensity also varied across people (see also Table 5B of Appendix B).

Overall, it never exceeded a mean value of 0.36 , thereby being always rather weak. However, the values range is fairly wide, spanning from a minimum of 0.001 for Sadness to a maximum of 0.749 for Delight. According to the mean intensity, Delight was the most intense emotion in terms of subjective feeling, whereas Anger was the least intense one.

An exploratory data analysis (EDA, Komorowski et al., 2016) has been conducted to yield information about the distributions of intensities using skewness and kurtosis constraints (Nuzzo, 2019).

Data observed for subjective feelings of primary and complex emotions are characterized by non-symmetric and non-identical distributions (see Table 3). Bittersweetness, Delight, and Surprise have a closer-to-normal distribution of intensities and outliers within it. 
BODILY SENSATION MAPS IN NEW MEDIA VISUAL ART ENCOUNTERS [PREPRINT]21

\section{Table 3}

Descriptive statistics of each emotion, the last column shows the overall values

\begin{tabular}{|c|c|c|c|c|c|c|c|c|c|c|c|}
\hline & Anger & Disgust & Fear & Happ. & Sad. & Surp. & Bitter. & Delight & Despair & Repug. & $\overline{\text { Overall }}$ \\
\hline Valid & 18 & 30 & 25 & 28 & 28 & 33 & 28 & 35 & 29 & 27 & 281 \\
\hline Median & .140 & .180 & .200 & .215 & .225 & .230 & .315 & .380 & .350 & .370 & .259 \\
\hline $\begin{array}{l}\text { Std. } \\
\text { Deviation }\end{array}$ & .0962 & .107. & .153 & .103. & .149 & .120 & .120 & .125. & .103 & . 128. & 139 \\
\hline Skewness & .450 & 1.305 & 1.057 & .212 & .874 & .826 & .294 & .617 & -.265 & -.058 & .455 \\
\hline $\begin{array}{l}\text { Std. Error of } \\
\text { Skewness }\end{array}$ & .536 & .427. & .464 & .441 & .441 & .409 & .441 & .398 & .434 & .448 & . 145. \\
\hline Kurtosis & -1.157 & 3.120 & 1.203 & -.462 & .403 & 1.359 & .141 & .818 & -.919 & -.922 & -.120 \\
\hline $\begin{array}{l}\text { Std. Error of } \\
\text { Kurtosis }\end{array}$ & 1.038 & .833 & .902 & .858 & .858 & .798 & .858 & .778 & .845 & .872 & .290 \\
\hline
\end{tabular}

Note. Happ. = Happiness; Sad. = Sadness; Surp. = Surprise; Bitter. = Bittersweetness.

Repug. $=$ Repugnance

Anger's negative kurtosis value shows a platykurtic distribution, that is slightly flatter than normal. Both Fear and Disgust are characterized by a tall right-skewed distribution, outside the range of normality (Hair et al., 2017). Besides, they both also show a skewness greater than 1, which reveals the presence of a wide left shoulder in the distribution indicating a large portion of weak intensity values. Furthermore, an EDA was performed using the medians as a measure of central tendency. The positional averages of Delight and Repugnance are very close (see Table 4), with the highest values of average intensity.

Conversely, Anger showed the lowest values of both average intensity and standard deviation, indicating a small dispersion of values. Instead, Sadness was characterized by the highest level of dispersion in intensity. A close-to-normal distribution can be observed when averaging the intensity of emotions across all affective states and stimuli. Such distribution has a low propensity for producing outliers, according to the cutoff values of skewness and kurtosis described by Westfall (2014).

\section{Art-elicited emotion-specific bodily sensation maps}

The characteristics of art-elicited emotions in terms of bodily sensations have been first explored using a chi-square test of independence. Specifically, this test investigates the 
relation between art-elicited emotions and (de)activated body regions (see Table ${ }_{5} \mathrm{C}$ and Table $7 \mathrm{C}$ in Appendix C).

Emotion showed a significant relation with both Activations $\left(\chi^{2}(40, N=7336)=\right.$ $305.370, \mathrm{p}<.001)$ and Deactivations $\left(\mathrm{X}^{2}(40, \mathrm{~N}=4896)=176.176, \mathrm{p}<.001\right)$, indicating that unique patterns of bodily sensations are associated with specific art-elicited emotions.

\section{Table 4}

Color-coded table summary of the p-values (2-tailed) obtained by Wilcoxon tests against the neutral state with exact significance correction.

\begin{tabular}{clcccrrr}
\multirow{2}{*}{$\begin{array}{c}\text { Subjective } \\
\text { feeling }\end{array}$} & \multirow{2}{*}{$\begin{array}{c}\text { Body } \\
\text { activity }\end{array}$} & Head & Chest & Abdomen & L_Limbs & U_Limbs \\
\cline { 3 - 7 } Anger & Activation & 0.138 & 0.061 & 0.079 & 0.688 & 0.288 \\
& Deactiv. & 0.922 & 0.567 & 0.648 & 0.010 & 0.019 \\
\hline \multirow{2}{*}{ Disgust } & Activation & 0.409 & 0.087 & 0.672 & 0.724 & 0.626 \\
& Deactiv. & 0.946 & 0.448 & 0.615 & 0.053 & 0.280 \\
\hline \multirow{2}{*}{ Fear } & Activation & 0.752 & 0.625 & 0.547 & 0.129 & 0.618 \\
& Deactiv. & 0.616 & 0.697 & 0.561 & 0.615 & 0.209 \\
\hline \multirow{2}{*}{ Happiness } & Activation & 0.072 & 0.002 & 0.001 & 0.005 & 0.005 \\
& Deactiv. & 0.003 & 0.054 & 0.032 & 0.019 & 0.026 \\
\hline \multirow{2}{*}{ Sadness } & Activation & 0.975 & 0.143 & 0.306 & 0.598 & 0.304 \\
& Deactiv. & 0.127 & 0.358 & 0.087 & 0.271 & 0.709 \\
\hline \multirow{2}{*}{ Surprise } & Activation & 0.273 & 0.142 & 0.841 & 0.267 & 0.175 \\
& Deactiv. & 0.069 & 0.034 & 0.111 & 0.624 & 0.576 \\
\hline \multirow{2}{*}{ Bittersweetness } & Activation & 0.808 & 0.214 & 0.025 & 0.167 & 0.361 \\
& Deactiv. & 0.284 & 0.898 & 0.389 & 0.395 & 0.288 \\
\hline \multirow{2}{*}{ Delight } & Activation & 0.001 & 0.000 & 0.000 & 0.007 & 0.001 \\
& Deactiv. & 0.075 & 0.065 & 0.001 & 0.000 & 0.000 \\
\hline \multirow{2}{*}{ Despair } & Activation & 0.180 & 0.006 & 0.012 & 0.001 & 0.002 \\
& Deactiv. & 0.070 & 0.011 & 0.010 & 0.076 & 0.077 \\
\hline \multirow{2}{*}{ Note. } & Activation & 0.904 & 0.382 & 0.027 & 0.058 & 0.212 \\
& Deactiv. & 0.048 & 0.058 & 0.028 & 0.517 & 0.292 \\
\hline
\end{tabular}

Note. The green (light gray) cells indicate statistically significant different body activity from the neutral state, while red (dark gray) cells show no statistically significant differences. L_Limbs = Lower Limbs; U_Limbs = Upper Limbs; Deactiv. = Deactivations. 
A closer examination of the body regions that are (de)activated showed that activation arises mainly on the head and often on the chest, whereas deactivation is more likely to occur on the lower and upper limbs. In the light of this finding, a control analysis of frequencies has been conducted to ensure the prominent activations in the head and chest are not related to what is depicted in the stimuli selection (human figures or miscellaneous contents, see Appendix F for detailed information). It revealed that activations at the level of the head are not typical only of stimuli picturing human faces or body parts as it can be similarly found in responses to stimuli containing food, landscapes, and monsters.

Nonetheless, stimuli depicting humans (especially half-length portraits) seem to elicit more distinguishable bodily activations in the upper part of the body and better discerned from the deactivations in the lower limbs, possibly suggesting a mirroring of embodied sensations (Gallese, 2006).

\section{Figure 5}

Dendrogram of Emotions using Complete Linkage

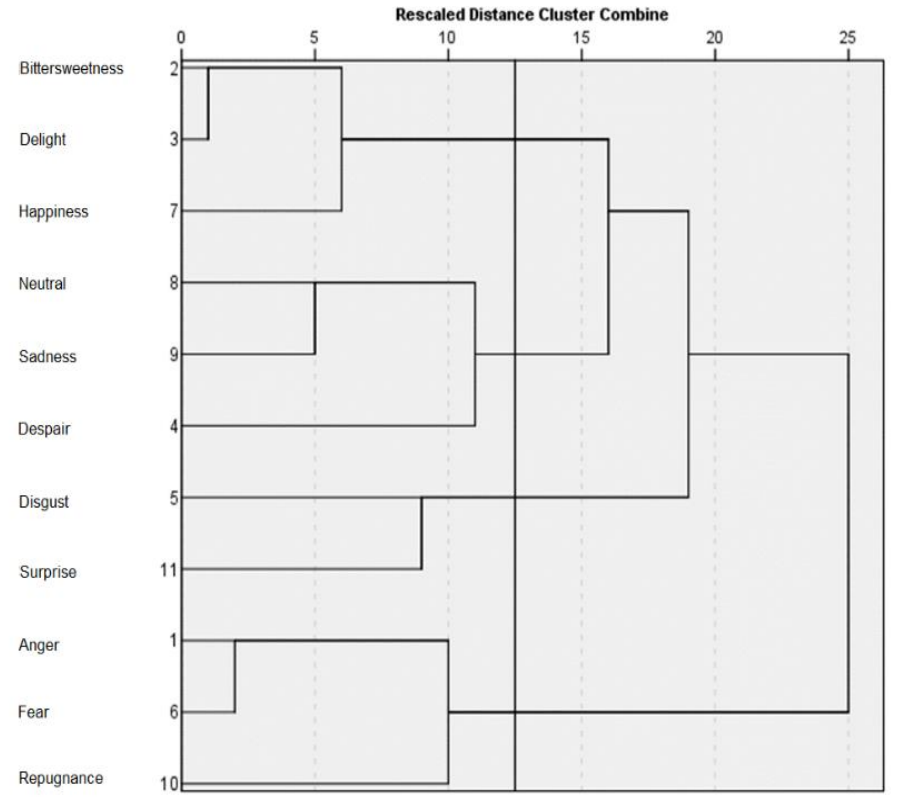

Note. The dendrogram shows a hierarchical structure of the similarity between bodily topographies of art-elicited emotions. Each emotion took into analysis constitutes its own cluster $(\mathrm{N}=11)$ numbered from 1 (case of Anger) to 11 (case of Surprise). See Appendix E for detailed information. 
Disgust, Fear, and Sadness were the only art-elicited emotions that did not show a statistically significant difference from the neutral state in any of the body regions, as analyzed with a Wilcoxon test (see Appendix D). Anger is characterized by a significant difference in the upper and lower limbs. However, this might be due to the smaller sample size of Anger compared to Neutral. On the other hand, Despair, Happiness, and Delight showed significant differences in most of the body regions, pointing out that their related bodily sensations can easily be distinguished from neutral states. Surprise and Bittersweetness differ from the neutral state only in the deactivation of the chest area for the former, and in the activation in the abdomen for the latter. Finally, Repugnance exhibited significant differences in the activation of the abdomen and the deactivation in the head region. Subsequently, art-elicited emotions have been clustered based on their counts using hierarchical clustering. The resulting dendrogram is shown in Figure 5 and allows the assessment of the grade of similarity among the counts of activations and deactivations in the BSMs. In analogy with the work by Nummenmaa et al. (2014), an agglomerative procedure with complete linkage (maximum distance) has been performed. This method is also known as "furthest neighbor" since it defines the distance between two groups as the distance between their two farthest-apart members. The clusters obtained are well separated and compact (see Appendix E) the observed distances are automatically rescaled by SPSS to fall into the range from 1 to 25 as shown in figure 5 . This means the actual distances cannot be observed but "the ratio of the rescaled distances within the dendrogram is the same as the ratio of the original distances" (Norušis, 2012, p. 384). The smallest rescaled distance is the one between Bittersweetness and Delight. According to the dendrogram, these two emotions are the closest in terms of the features considered. An arbitrary cutoff value has been determined at a distance of 12.5. All art-elicited emotions can join a cluster upon the threshold. At this point, four main clusters can be identified: one composed of Bittersweetness, Delight, and Happiness; another including Sadness, Despair, and Neutral; a third one grouping Disgust and Surprise, and the last cluster that contains Anger, 
Repugnance, and Fear. Ultimately, we can distinguish two big clusters, one for Anger, Repugnance, and Fear and the other comprising all the remaining art-elicited emotions.

\section{Discussion}

The main objective of this study was to assess the suitability of BSMs for quantifying the emotions elicited by 36 new media artworks. To this end, the interrelations between three factors were considered: (i) perceived bodily sensations, (ii) experienced subjective feelings, and (iii) artistic stimuli.

A degree of association between bodily sensations and artworks was observed. Notably, whenever the bodily sensation involved an activation, more points were collected in comparison to deactivation. This led to the conclusion that when the activity in the body is getting stronger, it is better perceived by viewers. Accordingly, Lyons et al. (2020) conducted a study where depressed and healthy adults were asked to self-report via BSMs their feelings towards emotion stimuli taken from the International Affective Picture System (IAPS). They reported that the percentage of deactivations in the total area painted by healthy individuals was $24 \%$ throughout their entire experiment, while we can infer that the remaining $76 \%$ has been painted as in corresponding to activations in the body. BSMs painted by depressed individuals, on the other hand, showed less activation overall (percentage of deactivation was $38.76 \%)$. These results suggested that, regardless of the stimuli used, the overall number of deactivations is usually less than the activations reported. As recommended by previous literature (Blazhenkova \& Dogerlioglu-Demir, 2020; Nummenmaa et al., 2018; Torregrossa et al., 2018; Volynets et al., 2019), the number of deactivations could be subtracted by the activations and for each body part without a loss of information in the analysis, thus proposing the use of activations as might be more accurate and applicable to future measurements in artistic encounters.

Figure 6 displays the bodily sensations in art-elicited emotions, mapping the patterns of bodily sensations within the ROIs. Results show that each art-elicited emotion is characterized by a unique pattern even within the same region. For instance, although both Sadness and Happiness show activation in the head, the former has a distinctive activation 
pattern on the eyes while the latter on the mouth. Conceivably, one might parallel this finding to the tears shed during a sad feeling or the smile when experiencing happiness. These reports of activation of the head and upper chest can possibly be connected to physiological responses, such as facial musculature micromovements and heart rate variation (Levenson, 2003). They could derive from the mirroring of emotions and sensations detected by our perception (Gallese, 2006). One's experience of emotions can be affected by what one sees and it can result in simulating and embodying a shared body state. Hence, the high amount of activations in the upper body found in the present study could reflect a mimicry of the artworks' contents (namely, faces, full-body, or half-bust pictures). Although Nummenmaa and colleagues (2014) suggested BSMs can report the effects of the autonomic nervous system too (2014, p. 4). Thus, people indicating feelings getting stronger in the head could be related to brain activation that derives either from mirroring the emotion expressed in the artwork (Wicker et al., 2003) or from triggering emotional imagery (Costa, 2010). Supporting the latter, Figure 6 shows that also the neutral state is related to activation of the head. This outcome conceivably results from the type of stimuli employed (visual artworks). Nummenmaa et al. (2014) used short stories and videoclips to collect emotion-induced BSMs. In their experiment with emotional movies, participants were presented with short 10-second movies without sound and depicting humans involved in either emotional or non-emotional activities (Nummenmaa et al., 2014). The emotioninduced BSMs resulting from such an experiment reported head activation in every emotion, with the exception of the neutral condition, strikingly contrasting our findings. Even if both the videoclips and the artworks used in the present study displayed human bodies and faces, they evoked different responses when it came to the neutral state. This may suggest that BSMs as a response to viewing human figures do not unequivocally result in mirrored bodily feelings. Interestingly, Nummenmaa and colleagues' (2014) results about emotion-induced BSMs after reading emotional stories are much more similar to the present findings displayed in Figure 6. The text-driven emotion induction triggered an activation at the level of the head in each of the basic emotions, even the neutral state. Therefore, it has been 
inferred that guided mental imagery based on reading short stories can be the source of reporting head increased activity. This is in accordance with our findings concerning visual artworks, suggesting that visual art, as well as narrative, potentially generates some level of cognitive, associative activation represented by the increased activity of the head region as a common thread in every emotion-induced BSMs.

In the BSM created for the emotion of delight, a generalized activation can be clearly observed throughout the whole silhouette aside from lower limbs. Specifically, one could see a pattern of activation mostly focused along the spine and deactivations imbuing the lower limbs, which might resemble the concept of 'chills' of pleasure representative of a condition of enjoyment (cf. Wassiliwizky et al., 2015). It is well known that positive emotions that bring pleasure, as delight here might constitute an example here, are traditionally the most associated with encounters between audience and artworks (for a comprehensive overview see Pelowski et al., 2016). Future studies could elucidate further the somatotopic responses to such an emotion. Although delight was the most chosen emotion throughout this study, art also triggered negative emotions. For instance, the combination of fear and sadness (i.e., despair) was the fourth emotion that occurred the most, followed by repugnance, and sadness (see Figure 3). This finding confirms that artworks can elicit various and complex emotions, ranging from highly positive to extremely negative (Cooper \& Silvia, 2009). In contrast to Cooper \& Silvia (2009), anger was observed less frequently than expected, indicating either that it is not common to experience anger in artistic encounters or that the chosen stimuli were not appropriate to elicit it. Hence, artwork selection is crucial for a comprehensive analysis of a range of art-elicited emotions. To investigate this further, a stimuli validation step could be implemented in future research. This could be done by performing a preliminary survey on a broad collection of stimuli, similar to the one performed by Novembre et al. (2019) in their study. Then, only the top hits in terms of intensity and agreement of dominant emotion would be used for the experiment. The artworks used in the present study did not appear to trigger intense emotions, leading to lower accuracy of the counts. This can also be seen with the rate of agreement of the 
emotions per stimulus, as it is often rather low ( $\leq 40 \%)$. In addition, the responses obtained seemed unbalanced, some art-elicited emotions were experienced more often than others. This resulted in unequal counts rendering some BSMs less reliable than others as is in the case of anger. Due to the individual differences underlying an emotional experience, studies could make use of analysis that accounts for individual-level and group-level variation.

Nevertheless, the collection of stimuli used in this study evoked both basic and complex emotions, constituting likely a starting point to create an open database of new media artworks. Future studies could approach the limitations of the present experimental design, and provide new attempts to design a standardized set of visual art stimuli for studying art-elicited emotions. The range of artworks could be extended to include artworks able to elicit a broader spectrum of emotions and intensities and to increase the applicability of BSMs as a research tool that overcomes language constraints.

All art-elicited emotions examined in the present research seem to follow similar sensation patterns in the body. A general deactivation of lower limbs and increased activity in the head and hands are common defining features across the art-elicited emotions experienced as a response to the artworks selected for this study. One might appreciate that all the body regions that are less prone to activation are instead more susceptible to deactivation. Interestingly, anger stands out from this pattern showing almost the same activation level in the head as much as in the upper limbs, especially the hands. Bias due to its low occurrence is plausible. Additionally, happiness is the only art-elicited emotion in which the chest obtained a score higher than the head. In this study, we confirmed that specific topographical distribution of bodily sensations can be tested in emotional categories, as previously described by Nummenmaa et al. (2014). Similar conclusions were drawn in previous studies (García- Magariño, Chittaro, \& Plaza, 2018; Jung et al., 2017; Novembre et al., 2019), which corroborate the idea that BSMs are "the most accurate description available to date of subjective emotion-related bodily sensations" (Nummenmaa et al., 2014, p. 3). 


\section{Figure 6}

BSMs of basic and complex emotions associated with the new media visual artworks in this study.

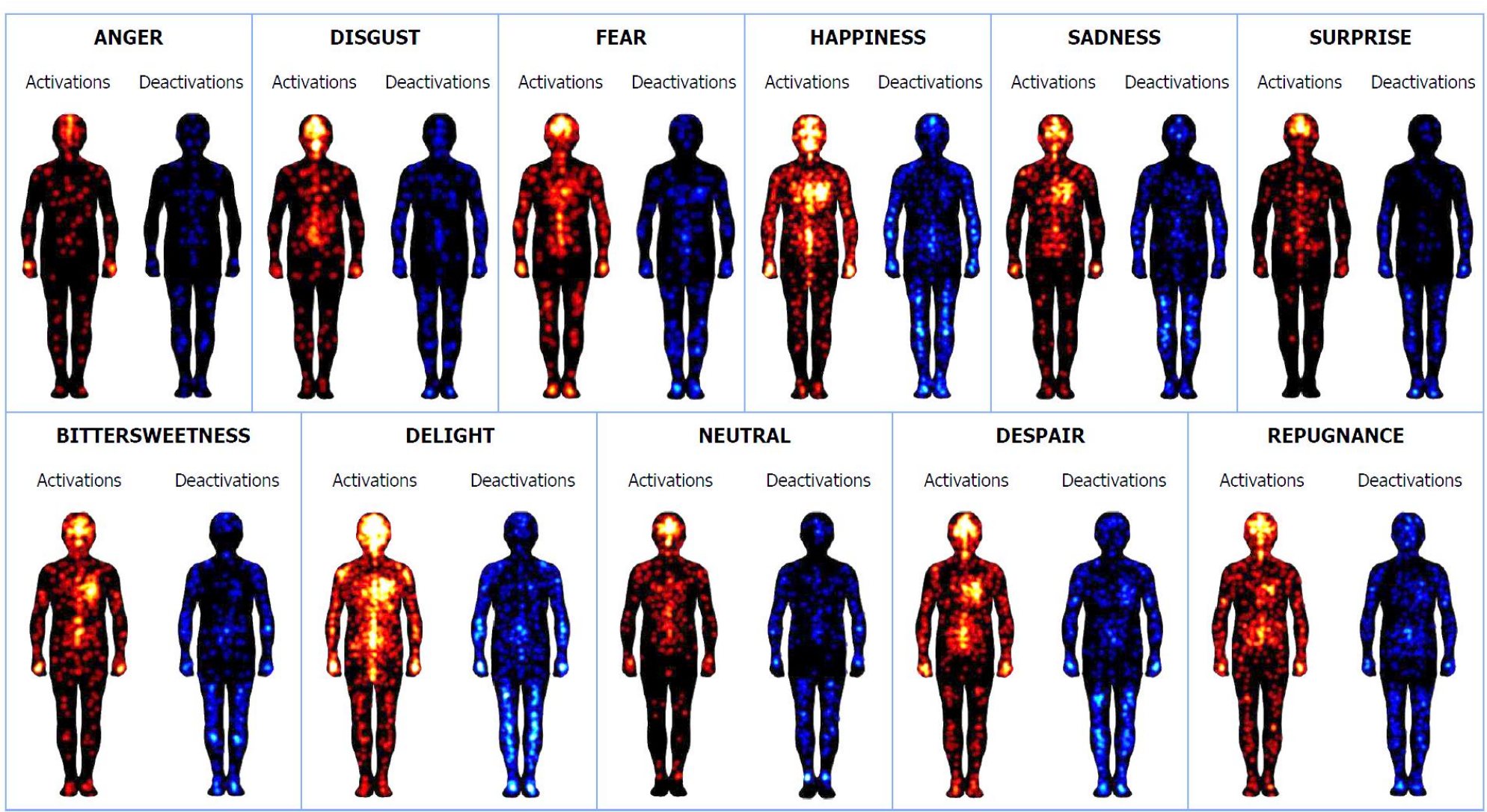

Note. The topographical depictions of basic emotions are on the first row, while the complex ones and the neutral state are on the bottom row. Brighter colors indicate a higher density of point-clicks. 
However, their application in representing art-elicited emotions shows some specific features compared to the ones found in other contexts. In our study, complex emotions show a higher degree of bodily sensations compared to basic emotions. The patterns visible in complex emotions correspond to the combination of their respective basic emotions. For instance, the superimposition of the silhouette of fear and sadness is remarkably like the one of despair. This supports Plutchik's theory (1980), which considers complex emotions as a combination of basic ones. However, according to his theory, the fusion of basic emotions may lead to a phenomenally different emotion. On the contrary, our findings may suggest a method of combination similar to the one described by Izard (1997), which is a mixture of basic emotions that preserves the phenomenal qualities of the derived emotion.

In line with Nummenmaa et al. (2014), the cluster analysis provided a cluster for positive emotions (see Figure 5). However, Nummenmaa et al. (2014) discovered four groups for negative emotions while in this study only one group was observed, comprising neutral, despair, and sadness. Possibly, this can be due to the higher number of emotions that were analyzed by Nummenmaa et al. (2014). Besides, in our study, the group composed of fear, anger, and repugnance was found to be clustered independently from other emotions. Finally, Nummenmaa et al. (2014) clustered surprise separately from other emotions, while we grouped it with disgust. According to the localization of bodily sensations, disgust and surprise seem to be close to each other. This considerably differs from what was previously observed, as surprise was not characterized by the activation of the abdomen (Nummenmaa et al., 2018). An interesting relationship was found between disgust and delight in many stimuli. For instance, in Stimulus 5 (see Appendix A) they were the first and second most chosen emotions, respectively. Delight is a combination of happiness and surprise, hence the similarity in the sensation pattern between surprise and disgust may be involved in this relation. Stimulus 10 represents the only stimulus in which disgust was the most prominent emotion without any apparent delightful implication. Investigating such linkages could be subject to future studies. 
All in all, BSMs appear to reflect the consciously accessible bodily sensations of artelicited emotions. Thus, they can be adopted for future studies as they can report a complex pattern of results of both complex and simple emotions in an intuitive and reliable way. However, they first need further validation in the field of psychology of art. The present study constitutes a first exploration in which BSMs were labeled with a series of fixedresponse alternatives to ensure the methodological efficiency of the data. Nevertheless, it represents a limitation of this paper. Although in the present study participants were asked to respond with the closest alternative to label their bodily sensations, there is a possibility they wanted to opt for a category that was not provided during the experiment and that this led them not to answer the question instead, establishing a constraint in the present design. Future studies could provide a residual "other" category as well as a "neutral” (or "none") one, such as in the case of the Geneva Emotion Wheel (GEW, Tinio \& Gartus, 2018). This would confirm the neutral option is deliberately chosen by the participants.

Furthermore, particular care must be given to the selection of new media artworks since they are pivotal for determining the quality of elicited emotions. The artwork collection employed here prevented a full validation for the full emotional spectrum as some emotions were less represented than others. Connections between physiological and emotional activation were confirmed using BSMs. Yet relying on self-awareness (i.e., introspective and interoceptive processes) exclusively may not be sufficient for complete exploration. However, validating the application of BSMs as a new research methodology in the art domain could constitute a step to bridge phenomenology and cognitive science, introspection and embedded cognition, strengthening or perhaps challenging existing models developed on the nature of emotions provoked by art (see Menninghaus et al., 2019; see also Skov \& Nadal, 2019). In this regard, it is important to mention that emotion theories, including Ekman's (1970; 2016) and Plutchik's (1980; 1982; 1991) models on basic and complex emotions applied in the current study, are not set to be definitive guidelines as the present research aims at providing evidence for using BSMs to explore this complex matter. Arrangements around the categorization labeling and reference models are still tentative and wait for 
confirmation or disproof upon various kinds of studies of self-reported bodily sensations of emotions elicited by art potentially through the use of BSMs.

BSMs can be used in the future to additionally study different aspects of human-art interaction, such as differences among the embodied emotional engagement of the artists and audience, or the individual relationship with specific artworks investigating, for instance, the impact of artistic style on viewers. In fact, the findings provided by this research are not to be generalized to all kinds of visual art encounters. In this paper, we focused our stimuli selection on figurative art, which is more likely to reflect the depicted emotion in the viewer (Kandel, 2016). Abstract art, on the other hand, is known to offer the viewers space for their own imagery and emotions. BSMs may be useful to map the emotions perceived in the sight of both these styles and investigate whether bodily sensations are perceived differently. Indeed, different styles and content of visual artworks may elicit different reactions. While we can infer figurative art may activate stereotypical answers, mirroring what we see in the work of art (for instance, activations in the head to indicate a smile seen on the depicted character), the way abstract art elicits emotions in people represents more of a mystery. Would it be able to elicit the same patterns of bodily sensations as the figurative one? Additionally, the use of BSMs can be extended to art forms outside the visual arts (e.g.: plastic arts, performing arts, music, and so on). Further finetuning in this direction will further corroborate this methodology as a powerful biomarker for bodily sensations in artistic encounters too.

Thanks to the body maps with regards to art-elicited emotions provided by this study, BSMs may be used to infer the subjective feeling evoked by artworks without directly asking for it. We may rely instead on the BSMs and look at how the body responds to art by the individual's conceptualization of physiological reactions.

\section{Conclusion}

We explored art-elicited emotions as a key output of the human-art interaction by applying Bodily Sensation Maps (BSMs) to link perceived bodily sensations to subjective feelings. 
We observed that subjective feelings and bodily sensations activity are intertwined with artistic stimuli, confirming that BSMs are a reliable and easy-to-use method to gather emotion-related information. Nevertheless, the selection of artworks as stimuli is critical for acquiring balanced data for each emotion. Therefore, an additional stimuli validation step prior to the experiment would be suitable in future research.

The patterns of activation and deactivation points obtained were unique for each emotion and similar to the ones found by Nummenmaa et al. (2014). This indicated that emotions evoked by new media visual art appraisal are akin to emotions experienced in other contexts. Notably, every emotion-specific BSM was characterized by increased activity on the head, which indicates the cognitive effort in response to new media visual art. Such activity can also be appreciated when an artwork did not trigger any specific emotion. 


\section{References}

Blazhenkova, O., \& Dogerlioglu-Demir, K. (2020). The shape of the pill: Perceived effects, evoked bodily sensations and emotions. Plos one, 15(9), e0238378. https://doi.org/10.1371/journal.pone.0238378

Brinck, I. (2018). Empathy, engagement, entrainment: the interaction dynamics of aesthetic experience. Cognitive processing, 19(2), 201-213. https://doi.org/10.1007/s10339$\underline{017-0805-\mathrm{x}}$

Brown, S., Gao, X., Tisdelle, L., Eickhoff, S. B., \& Liotti, M. (2011). Naturalizing aesthetics: brain areas for aesthetic appraisal across sensory modalities. Neuroimage, $58(1)$, 250-258. https://doi.org/10.1016/j.neuroimage.2011.06.012

Cooper, J. M., \& Silvia, P. J. (2009). Action Tendency of Hostile Aesthetic Emotions. Empirical Studies of the Arts, p. 113. https://doi.org/10.2190/EM.27.1.f

Costa, V. D., Lang, P. J., Sabatinelli, D., Versace, F., \& Bradley, M. M. (2010). Emotional imagery: assessing pleasure and arousal in the brain's reward circuitry. Human brain mapping, 31(9), 1446-1457. https://doi.org/10.1002/hbm.20948

Cova, F., \& Deonna, J. A. (2014). Being moved. Philosophical Studies, 169, 447- 466. https://doi.org/10.1007/s11098-013-0192-9

Csikszentmihalyi, M. (1990). Flow: The psychology of optimal experience (Vol. 1990). New York: Harper \& Row.

Cupchik, G. C., \& Gebotys, R. J. (1988). The search for meaning in art: Interpretive styles and judgments of quality. Visual Arts Research, 38-50.

Cupchick, G. C. (2013). I Am, Therefore I Think, Act, and Express both in Life and Art. In R. Tone, \& J. Lang, Art and Identity: Essays on the Aesthetic Creation of Mind (pp. 6792). Rodopi.

Damasio, A., \& Carvalho, G. B. (2013). The nature of feelings: evolutionary and neurobiological origins. Nature reviews neuroscience, 14(2), 143-152. https://doi.org/10.1038/nrn3403 
Ekman, P. (1970). Universal Facial Expressions of Emotion. California Mental Health Research Digest, 8(4), pp. 151-158.

Ekman, P. (2016). What scientists who study emotion agree about. Perspectives on psychological science, 11(1), 31-34. https://doi.org/10.1177/1745691615596992

Eskine, K. J., Kacinik, N. A., \& Prinz, J. J. (2012). Stirring images: fear, not happiness or arousal, makes art more sublime. Emotion, 12(5), 1071. https://doi.org/10.1037/aoo27200

Esrock, E. J. (2010). Embodying art: The spectator and the inner body. Poetics Today, 31(2), 217-250. https://doi.org/10.1215/03335372-2009-019

Esrock, E. J. (2018). Einfühlung as the breath of art: six modes of embodiment. Cognitive processing, pp. 187-199. https://doi.org/10.1007/s10339-017-0835-4

Freedberg, D., \& Gallese, V. (2007). Motion, emotion and empathy in esthetic experience. Trends in Cognitive Sciences, pp. 197-203. https://doi.org/10.1016/j.tics.2007.02.003

Fuchs, T., \& Koch, S. C. (2014). Embodied affectivity: on moving and being moved. Frontiers in Psychology, 5: 508. https://doi.org/10.3389/fpsyg.2014.00508

Gallese, V. (2001). Mirroring, a liberated embodied simulation and aesthetic experience. neuroscience, 2, 661-670.

Gallese, V. (2006, October). Embodied simulation: from mirror neuron systems to interpersonal relations. In Novartis Foundation Symposium (Vol. 278, p. 3). Chichester; New York; John Wiley; 1999. https://doi-org.proxyub.rug.nl/10.1002/9780470030585.ch2

Gallese, V. (2017). Visions of the body. Embodied simulation and aesthetic experience. Aisthesis. Pratiche, linguaggi e saperi dell'estetico, 10(1), 41-50. https://doi.org/10.13128/Aisthesis-20902

García, A. N. (2019). Hannibal and the paradox of disgust. Continuum, 33(5), 554-564. https://doi.org/10.1080/10304312.2019.1641180 
Ganczarek, J., Ruggieri, V., Nardi, D., \& Belardinelli, M. O. (2015). Intersection of reality and fiction in art perception: pictorial space, body sway and mental imagery. Cognitive processing, 16(1), 233-236. https://doi.org/10.1007/s10339-015-0702-0

Gernot, G., Pelowski, M., \& Leder, H. (2018). Empathy, Einfühlung, and aesthetic experience: The effect of emotion contagion on appreciation of representational and abstract art using fEMG and SCR. Cognitive Processing, 19(2), 147-165. https://doi.org/10.1007/s10339-017-0800-2

Hair, J. F., Hult, G. T. M., Ringle, C. M., Sarstedt, M., \& Thiele, K. O. (2017). Mirror, mirror on the wall: a comparative evaluation of composite-based structural equation modeling methods. Journal of the Academy of Marketing Science, 45(5), 616-632. https://doi.org/10.1007/s11747-017-0517-x

Hayn-Leichsenring, G. U. (2017). The ambiguity of Artworks-a guideline for empirical aesthetics research with artworks as stimuli. Frontiers in psychology, 8, 1857. https://doi.org/10.3389/fpsyg.2017.01857

Hekkert, P., \& Van Wieringen, P. C. (1996). Beauty in the eye of expert and nonexpert beholders: A study in the appraisal of art. The American Journal of Psychology, 389407. https://doi.org/10.2307/1423013

Izard, C. E. (1997). Emotions and facial expressions: A perspective from Differential Emotions Theory.

James, W. (1890). The perception of reality. Principles of psychology, 2, 283-324.

Johnson, M. (1987). The Phylosophical Context of Objectivism. In M. Johnson, The Body in the Mind: the bodily bases of Meaning, Imagination, and Reasons (p. xxv). Chicago: University of Chicago Press.

Jung, W.-M., Ryu, Y., Lee, Y.-S., Wallraven, C., \& Younbyoung, C. (2017). Role of interoceptive accuracy in topographical changes in emotion-induced bodily sensation. PLoS ONE, p. e0183211. https://doi.org/10.1371/journal.pone.0183211 
Juslin, P. N. (2013). From everyday emotions to aesthetic emotions: Towards a unified theory of musical emotions. Physics of life reviews, 1O(3), 235-266. https://doi.org/10.1016/j.plrev.2013.05.008

Juslin, P. N. (2013). What does music express? Basic emotions and beyond. Frontiers in psychology, 4, 596. https://doi.org/10.3389/fpsyg.2013.00596

Kandel, E. R. (2016). A return to the two cultures. In Reductionism in Art and Brain Science: Bridging the Two Cultures (pp. 187-189). Columbia University Press.

Kapoula, Z., Adenis, M. S., Lê, T. T., Yang, Q., \& Lipede, G. (2011). Pictorial depth increases body sway. Psychology of Aesthetics, Creativity, and the Arts, 5(2), 186.

\section{https://doi.org/10.1037/a0022087}

Komorowski, M., Marshall, D. C., Salciccioli, J. D., \& Crutain, Y. (2016). Exploratory data analysis. Secondary analysis of electronic health records, 185-203. https://doi.org/10.1007/978-3-319-43742-2 15

Konečni, V. J. (2015). Emotion in painting and art installations. The American journal of psychology, 128(3), 305-322. https://doi.org/10.5406/amerjpsyc.128.3.0305

Leder, H., Belke, B., Oeberst, A., \& Augustin, D. (2004). A model of aesthetic appreciation and aesthetic judgments. British journal of psychology, 95(4), 489-508. https://doi.org/10.1348/0007126042369811

Levenson, R. W. (2003). Blood, sweat, and fears: The autonomic architecture of emotion. Annals of the New York Academy of Sciences, 10oo(1), 348-366. https://doi.org/10.1196/annals.1280.016

Lyons, N., Strasser, A., Beitz, B., Teismann, T., Ostermann, T., Anderle, L., \& Michalak, J. (2020). Bodily maps of emotion in major depressive disorder. Cognitive Therapy and Research, 45(3), 508-516. https://doi.org/10.1007/s10608-020-10195-0

Marković, S. (2010). Aesthetic experience and the emotional content of paintings. Psihologïa, 43(1), 47-64.

Martindale, C., Moore, K., \& Borkum, J. (1990). Aesthetic preference: Anomalous findings for Berlyne's psychobiological theory. The American Journal of Psychology, 53-80. 
Menninghaus, W., Wagner, V., Wassiliwizky, E., Schindler, I., Hanich, J., Jacobsen, T., \& Koelsch, S. (2019). What are aesthetic emotions?. Psychological review, 126(2), 171. https://doi.org/10.1037/revooo0135

Menninghaus, W., Wagner, V., Hanich, J., Wassiliwizky, E., Jacobsen, T., \& Koelsch, S. (2017). Negative emotions in art reception: Refining theoretical assumptions and adding variables to the Distancing-Embracing model. Behavioral and Brain Sciences, 4O. https://doi.org/10.1017/S0140525X17001947

Millis, K. (2001). Making meaning brings pleasure: The influence of titles on aesthetic experiences. Emotion, 1(3), 320.

Norušis, M. J. (2012). IBM SPSS statistics 19 statistical procedures companion (Vol. 496). Upper Saddle River, NJ, USA:: prentice hall.

Novembre, G., Zanon, M., Morrison, I., \& Ambron, E. (2019). Bodily sensations in social scenarios: Where in the body? PLOS ONE, p. e0206270. https://doi.org/10.1371/journal.pone.0206270

Nummenmaa, L., Glereana, E., Harib, R., \& Hietanend, J. K. (2014). Bodily maps of emotions. PNAS, 111(2), 646-651. https://doi.org/10.1073/pnas.1321664111

Nummenmaa, L., Hari, R., Hietanen, J. K., \& Glerean, E. (2018). Maps of subjective feelings. Proceedings of the National Academy of Sciences, 115(37), 9198-9203. https://doi.org/10.1073/pnas.1321664111

Nuzzo, R. L. (2019). Histograms: A Useful Data Analysis Visualization. PM\&R, 11(3), 309312. https://doi-org.proxy-ub.rug.nl/10.1002/pmrj.12145

O’Hare, D. (1976). Individual differences in perceived similarity and preference for visual art: A multidimensional scaling analysis. Perception \& Psychophysics, 2O(6), 445452. https://doi.org/10.3758/BFo3208280

Ortony, A., \& Turner, T. J. (1990). What's basic about basic emotions?. Psychological review, 97(3), 315 .

Pelowski, M., Markey, P. S., Lauring, J. O., \& Leder, H. (2016). Visualizing the Impact of Art: An Update and Comparison of Current Psychological Models of Art Experience. 
BODILY SENSATION MAPS IN NEW MEDIA VISUAL ART ENCOUNTERS [PREPRINT]39

Hypothesis and Theory, 10(160), pp. 1-21.

https://doi.org/10.3389/fnhum.2016.00160

Pelowski, M., Markey, P. S., Forster, M., Gerger, G., \& Leder, H. (2017). Move me, astonish me... delight my eyes and brain: The Vienna integrated model of top-down and bottom-up processes in art perception (VIMAP) and corresponding affective, evaluative, and neurophysiological correlates. Physics of Life Reviews, 21, 80-125. https://doi.org/10.1016/j.plrev.2017.02.003

Plutchik, R. (1980). Emotion. A psychoevolutionary synthesis. New York: Harper and Row.

Plutchik, R. (1982). A psychoevolutionary theory of emotions.

\section{https://doi.org/10.1177/053901882021004003}

Plutchik, R. (1991). The emotions. University Press of America.

Prinz, J. (2004). Which emotions are basic? In Dylan Evans \& Pierre Cruse (eds.) Emotion, Evolution, and Rationality. Oxford: Oxford University Press, pp. 69-88.

Quaranta, D. (2014). Beyond new media art. Lulu Press, Inc.

Ribot, T. (1897). The psychology of the emotions. Walter Scott, Limited.

Rizzolatti, G., Fadiga, L., Gallese, V., \& Fogassi, L. (1996). Premotor cortex and the recognition of motor actions. Cognitive Brain Research, pp. 131-141. https://doi.org/10.1016/0926-6410(95)00038-0

Russell, J. A. (1991). Culture and the categorization of emotions. Psychological bulletin, 110(3), 426. https://doi.org/10.1037/0033-2909.110.3.426

Russell, J. A. (2003). Core affect and the psychological construction of emotion. Psychological review, 110(1), 145. https://doi.org/10.1037/0033$\underline{295 X .110 .1 .145}$

Scherer, K. R. (2005). What are emotions? And how can they be measured?. Social science information, 44(4), 695-729. https://doi.org/10.1177/0539018405058216

Silvia, P. J. (2009). Looking Past Pleasure: Anger, Confusion, Disgust, Pride, Surprise, and Other Unusual. Psychology of Aesthetics, Creativity, and the Arts, 3(1), pp. 48-51. https://doi.org/10.1037/ao014632 
Skov, M., \& Nadal, M. (2019). There are no aesthetic emotions: Comment on Menninghaus et al. (2019). Psychological Review, 127(4), 640-649. https://doi.org/10.1037/revooo0187

Sully, J. (1892). Outlines of Psychology, with Special Reference to the Theory of Education. New York, NY: D. Appleton and Company.

TenHouten, W. (2013). Emotion and reason: Mind, brain, and the social domains of work and love. Routledge. https://doi.org/10.4324/9780203093634

Tinio, P. P., \& Gartus, A. (2018). Characterizing the emotional response to art beyond pleasure: Correspondence between the emotional characteristics of artworks and viewers' emotional responses. Progress in brain research, 237, 319-342. https://doi.org/10.1016/bs.pbr.2018.03.005

Torregrossa, L. J., Snodgress, M. A., Hong, S. J., Nichols, H. S., Glerean, E., Nummenmaa, L., \& Park, S. (2019). Anomalous bodily maps of emotions in schizophrenia. Schizophrenia bulletin, 45(5), 1060-1067. https://doi.org/10.1093/schbul/sby179

Tracy, J. L., \& Robins, R. W. (2007). Self-conscious emotions: Where self and emotion meet. In C. Sedikides \& S. J. Spencer (Eds.), Frontiers of social psychology. The self (p. 187-209). Psychology Press.

van Klaveren, L.M., Ueding, M.L., \& Cox, R.F.A. (2019). Moving Art: Attunement in Artistic and Aesthetic Practices. In L. van Dijk \& R. Withagen (Eds.), Studies in Perception and Action $X V$. Taylor \& Francis Group, LLC.

Volynets, S., Glerean, E., Hietanen, J. K., Hari, R., \& Nummenmaa, L. (2019). Bodily maps of emotions are culturally universal. Emotion (Washington, D.C.), https://doi.org/10.1037/emoo000624

Wagner, V., Menninghaus, W., Hanich, J., \& Jacobsen, T. (2014). Art schema effects on affective experience: The case of disgusting images. Psychology of Aesthetics, Creativity, and the Arts, 8(2), 120. http://dx.doi.org/10.1037/ao036126 
Wassiliwizky, E., Wagner, V., Jacobsen, T., \& Menninghaus, W. (2015). Art-elicited chills indicate states of being moved. Psychology of Aesthetics, Creativity, and the Arts, 9(4), 405. http://doi.org/10.1037/aca0000023

Westfall, P. H. (2014). Kurtosis as peakedness, 1905-2014. RIP. The American Statistician, 68(3), 191-195. https://doi.org/10.1080/00031305.2014.917055

Wicker, B., Keysers, C., Plailly, J., Royet, J. P., Gallese, V., \& Rizzolatti, G. (2003). Both of us disgusted in My insula: the common neural basis of seeing and feeling disgust. Neuron, 4O(3), 655-664. https://doi.org/10.1016/So896-6273(03)00679-2 